\section{Introducing renewable energy in vineyards and agricultural machinery: A way to reduce emissions and provide sustainability}

\author{
Javier Carroquino, ${ }^{1,2}$ \\ Nieves García-Casarejos, ${ }^{3}$ \\ Pilar Gargallo ${ }^{3}$
}

${ }^{1}$ Department of Electrical Engineering, University of Zaragoza; ${ }^{2}$ Intergia Energía Sostenible S.L., Zaragoza; ${ }^{3}$ Faculty of Economics and Business, University of Zaragoza, Spain

\begin{abstract}
Climate change, depletion of nonrenewable resources in the current energies, pollution from them and the greater ecological awareness of the population, are factors that suggest the change of energy sources in business. The wine industry is concerned about sustainability and with a clear awareness of what climate change may mean for it. This sector is supposed to have a high receptivity to the implementation of clean energy, as this favours not only the environment but also the essence of its business. This work shows how the use of renewable energy, on a small scale, can be profitable in both vineyards and wineries. For this purpose, the European project LIFE REWIND (Renewable energy in the wine industry) has developed several actions, including the installation and operation of a prototype in a Spanish winery. This paper shows how to introduce renewable energy in wineries and vineyards in a profitable way, reducing the emissions of $\mathrm{CO}_{2}$ associated to the activity and the product, without changing the processes of cultivation or production.
\end{abstract}

\section{Introduction}

The search for sustainability is a necessary trend to consolidate the future of any economic activity. Viticulture is beginning to be affected by climate change, whose impacts may require important adaptation measures in the near future. ${ }^{1}$ In line with the diversity of wine regions, with their particular conditions and different wines produced, the impacts may be different and deserve to be studied. ${ }^{2}$ Probably few products are as sensitive as wine to climate variations. ${ }^{3}$ Therefore it is desirable that companies in the sector are not only prepared for their adaptation but also contribute as much as possible to mitigation actions, such as reducing emissions of greenhouse gases. These actions can be addressed in a variety of ways, requiring knowledge that should be contributed and shared within the sector, since its international application would benefit the whole of the sector. ${ }^{4}$ Another consideration to be taken into account is the gradual increase in the importance of product sustainability in the consumers' decision to purchase, especially in a product such as wine. $^{5}$

Energy used in agriculture is a source of greenhouse gas emissions. ${ }^{6}$ To reduce these emissions, the European project LIFE REWIND addresses the supply of this energy demand from renewable sources. In winemaking activities, the energy used is mainly obtained in three ways (Figure 1) extensions of the electricity grid, diesel generator sets and diesel for agricultural machinery and mobility. All three have significant environmental, emission or landscape impacts. Therefore, the use of renewable energy produced on-site would have great environmental advantages. In addition, positive socio-economic impacts can be obtained in the involved areas. ${ }^{7}$ There are many studies on renewable energy supply, especially for irrigation pumping, some of which have advanced in their specific study for Mediterranean crops, among which is the vine. ${ }^{8}$

\section{Materials and Methods}

Figure 2 shows a scheme of the process. First of all, the necessary information has been collected.

The main data sets are: i) Available renewable resources: obtained from on-site measurements in locations of wineries and vineyards, through sensor stations (Figure 3 ), as well as geographic information systems and even bibliographic references. The scope of the study of renewable resources was limited to the European areas with greater presence of the wine sector where, as a result of the climate and geographical latitude, a great variety of wind resources and a relative uniformity of the solar resource were found. ii) The energy demand from wineries: The electricity bills have been used to calculate the electricity demand of each winery through a one-year period. That is to say, the electricity consumption of the whole winery has been considered, without separating the consumption of the different processes taking place. iii) The energy demand from
Correspondence: Javier Carroquino, Coímbra 2, 50008 Zaragoza, Spain.

Tel.: +34.976364588

E-mail: javier.carroquino@intergia.es

Key words: climate change, renewable energy, irrigation, hydrogen, sustainability.

Contributions: JC, energy, hydrogen, optimizations, manuscript writing; NGC, PG, analysis of environmental and socio-economic impacts, sector and stakeholders surveys.

Acknowledgments: The authors wish to thank the LIFE Program of the European Commission for their financial support for the LIFE REWIND project (LIFE13/ENV/ $\mathrm{ES} / 000280)$.

Conflict of interest: the authors declare no potential conflict of interest.

Funding: The LIFE REWIND project, which is the origin of this work, was supported by the European Commission through the LIFE program.

Conference presentation: part of this paper was presented at the Fourth Edition of the International Conference Series on Wine Active Compounds (WAC2017) - 29, 30, 31 March 2017, Beaune, France.

Received for publication: 2 August 2017.

Revision received: 27 November 2017.

Accepted for publication: 27 November 2017.

This work is licensed under a Creative Commons Attribution NonCommercial 4.0 License (CC BY-NC 4.0).

(C) Copyright J. Carroquino et al., 2017

Licensee PAGEPress, Italy

Wine Studies 2017; 6:6975

doi:10.4081/ws.2017.6975

irrigation pumping in vineyards: In pumping powered by the mains, electricity bills has been collected. In pumping powered by diesel generator sets, recorded diesel consumption data has been collected. Qualitative data is also collected regarding irrigation needs, habits of use and possibilities of demand management, through interviews and questionnaires with the managers of the irrigation facilities. iv) The energy demand from agricultural machinery and mobility: data on use and consumption has been collected, when available. v) Internal subjective and objective parameters of the wineries (uses, attitudes about sustainability, etc.): it has been considered important to obtain both objective and subjective data from the owners or managers of wineries and vineyards. This includes issues such as 
willingness to incorporate renewable energy, incentives and restraints, manageability of systems, etc. For this, a survey has been drawn up in the Spanish wine sector. The objective of this is to know the penetration of renewable energies, to characterize the sector in terms of its geographical typologies, activity levels, its perception of environmental aspects, its degree of application of measures to mitigate the climate change or improve energy efficiency, and their uses about energy consumption. vi) External objective parameters (technical, economic, regulatory, etc.).

From there, the studies have been carried out with two large datasets. One related to the whole sector with its different typologies of vineyards and wineries. The other, with the demonstrative case, with its prototypes.

Secondly, the prototypes have been designed, using the best available technologies. ${ }^{9}$ With data obtained from energy demand and renewable resources, numerous simulations of renewable generation systems were carried out by computer. The search for optimal solutions was done with the simulation and optimization software iHOGA that uses genetic algorithms. ${ }^{10,11}$ This allows determining the size of renewable generation systems that minimize the cost of energy, $\mathrm{CO}_{2}$ emissions or both criteria. The operation of the prototypes has been monitored during a year of operation in real conditions, obtaining data that have allowed the validation of the previous calculations. These data include installation, operation and maintenance costs. User validation of the system has also been obtained.

Thirdly, two software tools have been developed, in order to facilitate the replication of the proposed systems. The first one can make a diagnosis of the feasibility of incorporating renewable energy in each specific installation, a winery, an irrigation pumping of a vineyard, etc. The second software tool helps technical sizing, which facilitates the replication of the proposed design, adapting it to each specific case.

Finally, the results were analysed, obtaining a set of conclusions on the ways and conditions to introduce renewable energy in the wineries and vineyards. At this stage, the results of the environmental impact studies, as well as the socioeconomic impact on the region and stakeholders, were also incorporated. The environmental impact of the prototypes have been measured by comparing the initial situation with the new situation, i.e., the use of the electricity grid in the wastewater treatment plant of the winery, a generator set in the irrigation pumping and a diesel vehicle, with a photovoltaic generation system and a vehicle with hydrogen fuel cell. The whole life cycle of the systems has been taken into account. In order to assess the socio-economic impact on the local population and society, the existing methodology has been explored, revising various options among those used for the assessment of socio-economic impacts. ${ }^{12}$ To assess the impact on stakeholders, the appropriate methodology has been determined to be the contingent valuation method. This method is included among the
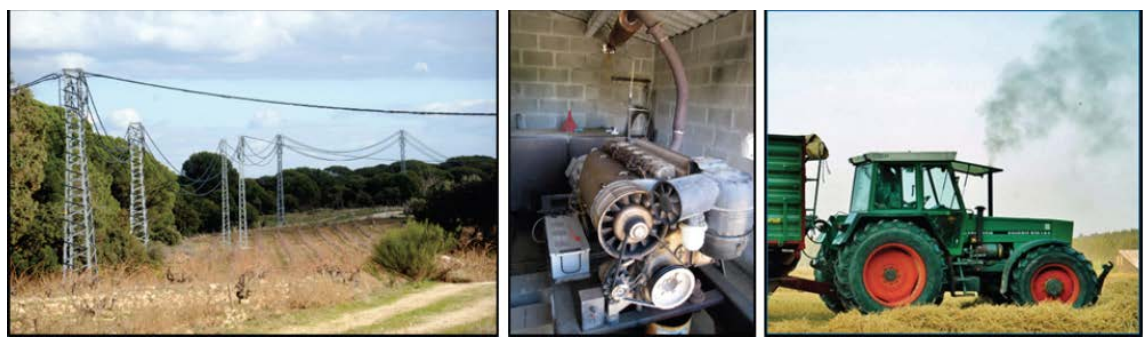

Figure 1. Extension of the electricity grid, diesel generator set and diesel agricultural machinery.

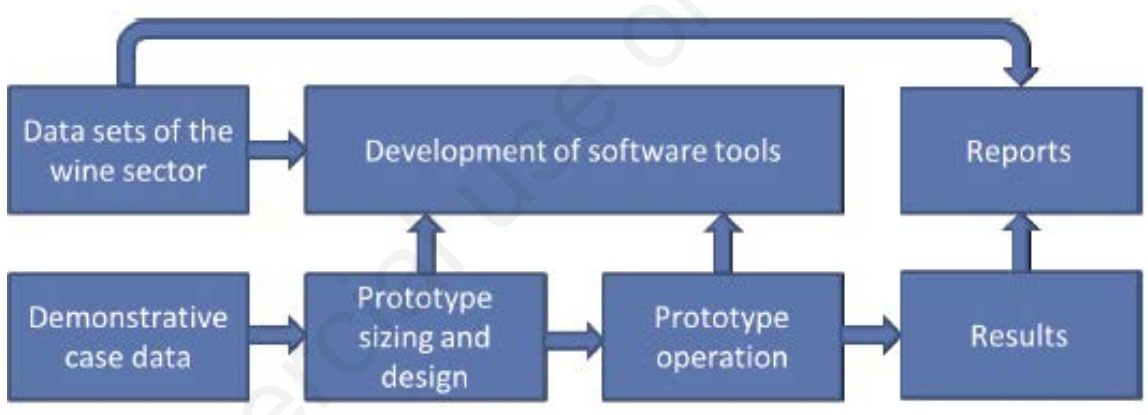

Dissemination

Figure 2. Scheme of the process.

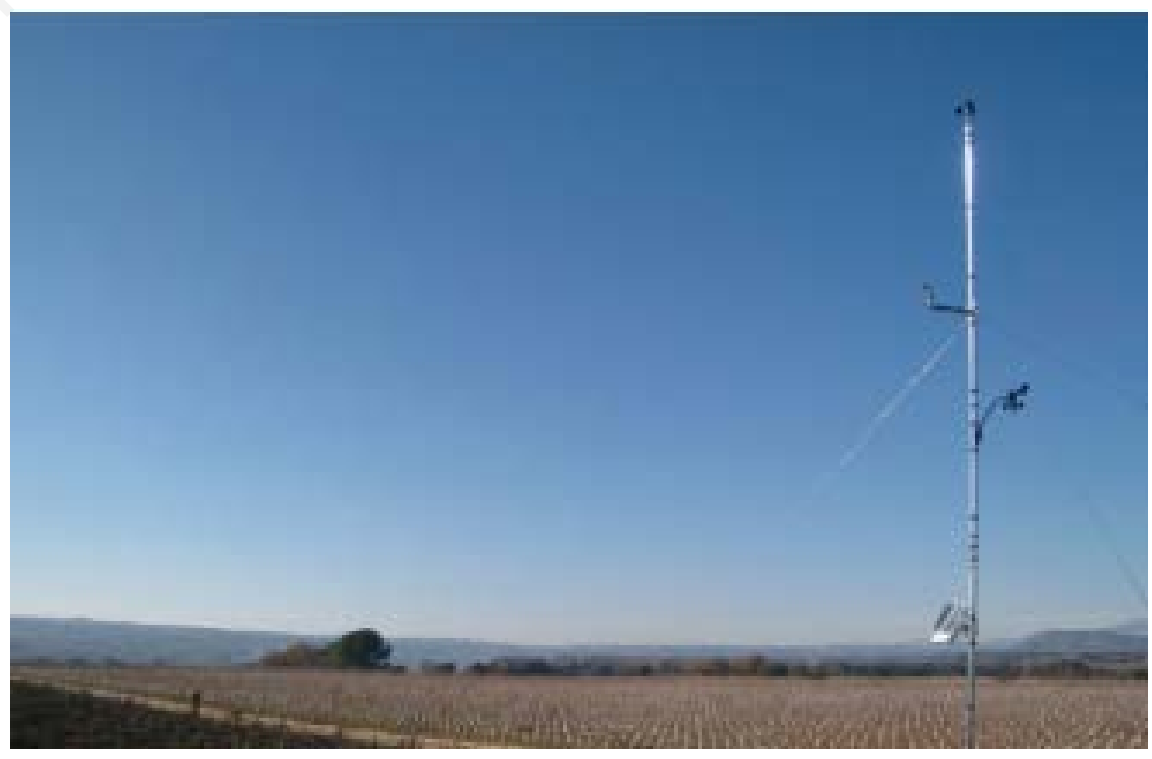

Figure 3. Solar and wind resource measurement. 
forms of direct evaluation by survey, and tries to measure in monetary units the changes in the level of welfare of the people and the satisfaction of the companies and institutions involved, due to the implementation of systems more respectful to environment. Throughout the whole project, communication and dissemination actions were developed, aimed at the general public and interested parties, with special emphasis on the final communication of results. The prototypes were conceived for a demonstrative use: they are visitable, equipped with informative panels and with explanatory leaflets for the visitors. In addition, from the internet it is possible to remotely access the high-definition motorized webcams, the control computer and the server that houses data on its operation and sensors, including graphics and statistics.

\section{Prototypes}

The prototypes are located in the Viñas del Vero winery and vineyard (Figure 4) in the wine region of Somontano (Spain).

Regarding the winery, the main consumption is electricity for refrigeration, bottling, small pumps, lighting and offices, including air conditioning. In this case, there is a wastewater treatment plant with its corresponding demand for electrical energy. This winery obtains electricity from the electricity grid, as is the most frequent. Because of this, in general the solution in the winery would consist of a set of photovoltaic generation in self-consumption connected to the grid, in such a way as to contribute with a fraction of the total electricity consumed by the winery. However, for a greater demonstrating effect and also because of the inappropriate Spanish regulation on selfconsumption, it was decided to identify a specific subset of the winery and to feed it to $100 \%$ with renewable energy, without connection to the electricity grid. The chosen installation was the wastewater treatment plant that purifies the water, used in the winery itself, for its later use in irrigation.
Thus, the wastewater treatment plant has been disconnected from the electricity grid and is fed from the renewable energy produced by the prototype, in a stand-alone energy system.

Regarding the vineyard, two main energy uses have been identified. One of them is the pumping of water for irrigation. The other is diesel for agricultural machinery and workers' mobility. The prototype has been designed to power the pumps of the drip irrigation system. It is the set of irrigation that uses the already purified water.

Both environments, winery and vineyard, present a seasonal energy demand profile, due to the seasonality of the processes (irrigation, vintage, winemaking, etc.). This has two important consequences. On the one hand, the seasonal profile of these energy demands is much better suited to the solar resource than to the wind resource. Thus the chosen type of renewable generation is photovoltaic. On the other hand, there is a need for long-term energy storage.

The prototype generates electricity by photovoltaic panels, mounted on three different sets (Figure 5) that allow comparisons and show different technical solutions. Special mention should be made of the floating set, specially designed for use in irrigation ponds with strong variations of level. The placement of the panels on the irrigation pond avoids the use, preparation and fencing of terrain. It is also expected to obtain positive effects such as the reduction of water loss of the pond by evaporation and the improvement of the thermal behaviour of the photovoltaic panels.

A set of inverters converts the produced electricity and creates an electric microgrid of similar characteristics to the electricity grid. From this microgrid, the pumps and other devices consuming electricity are fed.

Regarding energy storage, a set of leadacid batteries takes care of short-term storage. Since long-term battery storage is not technically and economically feasible, the prototype of the vineyard has been chosen to use surplus energy in the production of hydrogen by electrolysis of water, separating hydrogen from oxygen. Much of the energy used for it can again be recovered by the reverse process, combining hydrogen with oxygen in a fuel cell. In this way, the surplus energy is stored as hydrogen, in a high pressure tank. An allterrain electric vehicle has been transformed by incorporating a fuel cell, hydrogen tanks

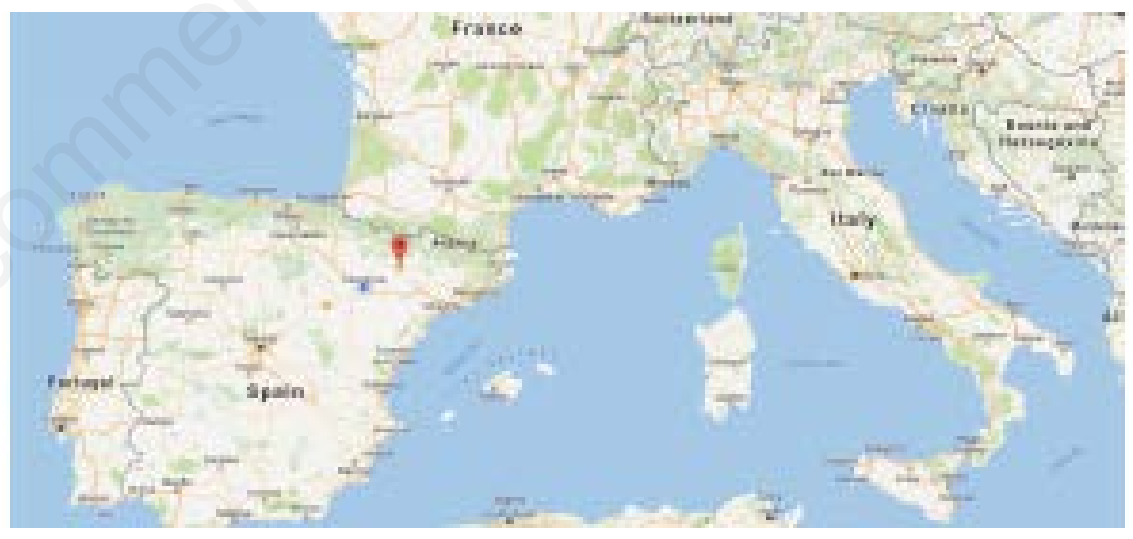

Figure 4. Location of the prototypes.
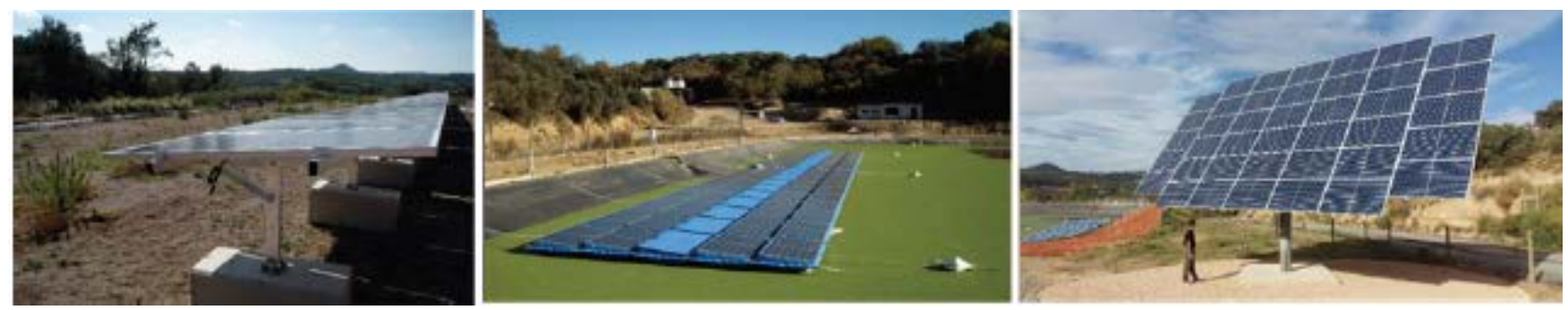

Figure 5. The three photovoltaic arrays: fixed, floating and solar tracker. 
and the necessary control systems. The vehicle is refuelled on site with hydrogen and is used for workers' mobility in the vineyard (Figure 6). This is a demonstrator of the possibility of replacing diesel by hydrogen in agricultural machinery or mobility on the farm itself.

In stand-alone generation systems, not connected to the grid, it is key to avoid periods where there is a lack of energy or others where it is wasted. Therefore, another of the innovations incorporated in the prototypes is an advanced control and management software of the energy. Some of the consumptions related to the purification are managed automatically, while others, such as irrigation, have been left to the discretion of the user, either manually or programmable. The system can be handled and monitored remotely with a computer, tablet or mobile phone connected to the internet. Also through the internet the installation can be monitored or shown, thanks to the existence of twomotorized webcams.

\section{Results, Discussion and Conclusions}

The definitive results, due to their extension and to still being in development, will be detailed in future publications of the energetic, environmental and socioeconomic fields. However, some qualitative results that clearly appear in the data already available can be mentioned.

\section{Results of the prototype}

The first year of operation, the amount of renewable electricity supplied to the wastewater treatment plant has been 53,902 $\mathrm{kWh}$, used for the depuration of $10,000 \mathrm{~m}^{3}$ of water. During the irrigation season, the amount of electricity supplied to the irrigation system has been $8,252 \mathrm{kWh}$, used for the irrigation of 10 ha of vine. In addition, $6,412 \mathrm{kWh}$ have been used to produce $109 \mathrm{~kg}$ of hydrogen, replacing the use of 1,010 litres of diesel.

Regarding the winery, replacing a fraction of the electrical energy consumed from the mains, whose generation mix includes coal, natural gas and nuclear, the associated emissions is avoided, as well as the production of radioactive waste. As far as irrigation pumping is concerned, replacing the diesel consumed in the generation of electricity that feeds the pumps, the emissions associated with the combustion of diesel are avoided. Likewise, replacing the diesel consumed by a vehicle in the vineyard, these emissions are avoided. The summary of emissions avoided is shown in Table 1.

\section{Attitude of the sector}

The penetration of renewable energies is still at low levels, being the most used energies, thermosolar, photovoltaic and biomass. The initial investment seems to be at the origin of the lack of implantation of this type of energy in the wineries, and not so much the operation and maintenance costs. If a change in this is desired, it will be necessary to establish mechanisms that could change the perception, or to design formulas in line with the financial possibilities of each winery. Among the motives provided by the wineries about their interest in implementing renewable energy, environmental sustainability stands out, which shows their awareness of climate change and its willingness to reduce emissions. The wineries focus on what constitutes their main activity, the production and sale of wine. Energy is not their business, which means that they need external information and advice for decision-making on it. The environmental management of the wineries is still at an embryonic stage within the company's organization chart and sometimes this function is not clearly identified. In small and medium-sized wine companies, this service is either outsourced or performed by a technical staff as a secondary task. Only in big companies, the existence of a technician or even a department to the environmental management is usual. However, there is a strong environmental awareness, as evidenced by the number of energy efficiency measures already adopted.
In addition, as the wineries are aware that the climate has changed, they would be willing to take measures to reduce $\mathrm{CO}_{2}$ emissions, which contrasts with the low implementation of this type of measures by the wineries, indicating that there is a wide path for improvement. Therefore, the proposal of actions in this sense could be well received. The gap between high awareness and low achievement is probably due to the lack of knowledge of how to do it or the perception of a high cost. To sum up, surveys show that wine companies would be willing to use renewable energy, if it is offered in a costeffective way.

\section{Technical issues}

Regarding vineyards, the energy demand is concentrated in agricultural machinery, mobility and, if there is, in irrigation pumping. Usually, electricity is obtained by extensions of the electricity grid or by on site diesel generator sets. The profile of energy demand of a vineyard presents a seasonal pattern, due to the seasonality of the processes, especially irrigation. This profile fits well with that of the solar resource, which favours the use of on site photovoltaic generation, without connection to the grid. Even with batteries to store energy, there are long periods where there is a surplus of energy that cannot be stored in a costeffective way. If a relatively small diesel (or gas) generator is included in the photovoltaic system, it is possible to reduce the number of photovoltaic panels and batteries and, therefore, the cost. With a good sizing and design of the system, the largest fraction of energy will be supplied by photovoltaic and

Table 1. Summary of avoided emissions.

\begin{tabular}{lcccccc} 
& $\begin{array}{r}\mathrm{CO}_{2} \\
(\mathrm{~kg})\end{array}$ & $\begin{array}{c}\mathrm{SO}_{2} \\
(\mathrm{~kg})\end{array}$ & $\begin{array}{c}\mathrm{NOX} \\
(\mathrm{kg})\end{array}$ & $\begin{array}{c}\mathrm{PM}_{2.5} \\
(\mathrm{~kg})\end{array}$ & $\begin{array}{c}\mathrm{PM}_{10} \\
(\mathrm{~kg})\end{array}$ & $\begin{array}{c}\text { Radioactive } \\
\text { waste }(\mathrm{g})\end{array}$ \\
Winery & 13,476 & 29.21 & 20.00 & - & - & 27.49 \\
\hline Vineyard (irrigation) & 7,040 & 0.0524 & 76.77 & 4.26 & 4.26 & - \\
Vineyard (vehicle) & 2,713 & 0.0202 & 29.581 & 1.64 & 1.64 & - \\
\hline
\end{tabular}
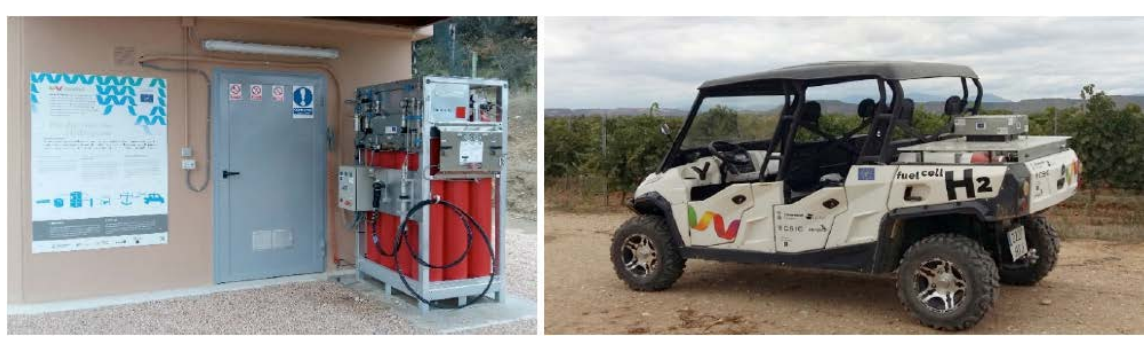

Figure 6. Hydrogen refuelling station and fuel cell vehicle. 
a small fraction by diesel. This hybrid solution can be the best in many real cases. The use of renewable energy for irrigation is already technically and economically feasible. The resulting energy costs depend on the characteristics of each case, being almost always inferior to the ones of diesel generation. In comparison to the extension of the electricity grid, depending on the cost of it, the proposed system of off-grid renewable generation can also be more profitable. In contrast, use of hydrogen to store energy or to power agricultural machinery is not yet profitable, waiting for its future technical and economic evolution.

Regarding wineries, their electricity demand also presents a seasonal pattern, although not as marked as that of irrigations. In most cases, wineries are grid connected. Therefore, photovoltaic generation can be installed in self-consumption mode, connected to the grid. The objective in this case is the on-site production of a fraction of the electricity needed. The rest is still taken from the grid and even the surplus, if any, can be sold through it. The prices of electricity extracted or transferred to the grid depend on the supply contract and the electricity tariffs of each country. A qualified study of each case is the key to a reliable and profitable installation. Photovoltaic panels can be mounted on building rooftops, car parks or other available surfaces with proper orientation. This allows integration of the generation in the existing installations, without causing any affection to their activities. In the wine sector, the proposed solutions will reduce the $\mathrm{CO}_{2}$ emissions associated with the process and the product. Since only the origin of the energy used is modified, no adaptation or modification of the viticulture or the vinification process is necessary.

Several studies are being prepared as a result of the data obtained during the development of the LIFE REWIND project concerning technical, economic, environmental and socio-economic results.

\section{References}

1. Mozell MR, Thach L. The impact of climate change on the global wine industry: Challenges \&amp; solutions. Wine Econ Policy 2014;3:81-9.

2. Lereboullet AL, Beltrando G, Bardsley DK. Socio-ecological adaptation to climate change: A comparative case study from the Mediterranean wine industry in France and Australia. Agric Ecosyst Environ 2013;164:273-85.

3. Rochard J. The vine; an emblematic plant bio-indicatrice of the climatic variations, presentation of project ADVICLIM / La vigne; une plante bioindicatrice emblématique des variations climatiques, présentation du projet ADVICLIM. BIO Web Conf 2016;7:1010. Available from: http://www.bio-

conferences.org/10.1051/bioconf/20160 701010

4. Szolnoki G. A cross-national comparison of sustainability in the wine industry. $\mathrm{J}$
Clean Prod 2013;53:243-51.

5. Fiore M, Silvestri R, Contò F, Pellegrini G. Understanding the relationship between green approach and marketing innovations tools in the wine sector. J Clean Prod 2017;142:4085-91.

6. Schneider UA, Smith P. Energy intensities and greenhouse gas emission mitigation in global agriculture. Energy Effic 2009;2:195-206.

7. Khaled R. The challenge of innovative method of culture more sustainable on the social aspect of rural areas: Empirical evidence from Mediterranean countries. Intellect Econ 2016;10:13344.

8. Carroquino J, Dufo-López R, BernalAgustín JL. Sizing of off-grid renewable energy systems for drip irrigation in Mediterranean crops. Renew Energy 2015;76:566-74.

9. Muhsen DH, Khatib T, Nagi F. A review of photovoltaic water pumping system designing methods, control strategies and field performance. Renew Sustain Energy Rev 2017;68:70-86.

10. Start-iHOGA software. [cited 2017 Aug 2]. Available from: https://ihogasoftware.com/en/

11. Dufo-López R, Bernal-Agustín JL. Design and control strategies of PVdiesel systems using genetic algorithms. Sol Energy 2005;79:33-46.

12. Kosenius AK, Ollikainen M. Valuation of environmental and societal trade-offs of renewable energy sources. Energy Policy 2013;62:1148-56. 